\title{
GAGA: NOTES ON THE MANAGEMENT OF PUBLIC IDENTITY
}

\author{
MAThieu DeFLEM
}

\begin{abstract}
Lady Gaga distinctively exemplifies the contemporary celebrity in popular culture because of the extent of her fame as well as the distinct persona she presents to her audience of both fans and onlookers. In this paper, I discuss how the persona of the person born as Stefani Germanotta was created and subsequently maintained in a variety of ways related to her naming as Lady Gaga. Invoking the work of Erving Goffman, my discussion extends beyond an analysis of the effectiveness and fame of Lady Gaga's presentation of self to the ensuing essence of her persona itself, that is, of Lady Gaga as Gaga rather than gaga. Not merely a brand, Lady Gaga is, in more ways than only economic, what Lady Gaga has become to herself and to others. As the performer slips in and out of the many public personae she has created in her name, I argue, she has become Gaga to the public at large and, with only minimal qualification, among her once personal friends and in the privacy of her socially constituted self. The truth that has to be acknowledged today is that Lady Gaga has indeed become Lady Gaga.
\end{abstract}

\section{KEY WORDS}

Lady Gaga; Self; Identity; Fame; Popular Music; Pop Star

\section{INTRODUCTION}

There have perhaps been only a few artists over the past decade that have captured the public imagination as much as Lady Gaga, and who have asserted their name, in some part because of their name, firmly in the pop culture lexicon. Lady Gaga is, of course, far from alone in inventing a moniker that effectively functions, whether by intent or not, to contribute to the construction of a public self. Bob Dylan, Freddie Mercury, Elton John, David Bowie, George Michael, Iggy Pop, and Elvis Costello are just a few of the pop and rock stars who invented a name for the stage of their music different than that of their birth. Lady Gaga was not even the first female singer to be explicitly named a lady, although Lady Bianca may not be well known outside a small circle of hard-core devotees of Frank Zappa, with whom the American R\&B singer briefly performed in the 70s. Nevertheless, as one part of Lady Gaga's focused attempt to climb to the top of the pop landscape, the choice of a name as strange and malleable as her persona has been anything but inconsequential.

In this paper, I contribute to the growing academic interest in Lady Gaga (Gray 2012; Iddon \& Marshall 2014) and the persona of artists (Marshall, Moore \& Barbour 2020, pp. 133153) by uncovering those aspects of the singer's public identity that relate specifically to her name and its sociological significance in establishing the singer's fame. Readers with some 
background in sociological theory will have noted the blatant allusion made in this paper's title to the famous work by Erving Goffman (1963) on stigma and the management of spoiled identity. As the name Lady Gaga will not evoke all too many negative connotations of exclusion, my discussion theoretically fits more broadly within the theoretical model Goffman (1956) suggested on the management of the self in public life. Informed by that perspective, my musings on the name Lady Gaga and the identity of the singer as both Gaga and gaga are framed within a constructionist framework that focuses on the conditions of the fame of the singer and its various dimensions. "What's in a name?" is the question that drives the analysis in this paper.

\section{DIMENSIONS OF FAME}

The study of fame and celebrity has developed well in recent years (Marshall \& Redmond 2016; Turner 2014) and has also begun to be applied to the world of music. Fame in music is particularly interesting, amongst other reasons, because both music and fame constitute social relationships, between the performer and the celebrity, on the one hand, and their respective audiences, on the other (Deflem 2017). The impact of these relationships is additionally amplified in the case of pop music because of the potential size of its audience. The fame of Lady Gaga is as undeniable on a global scale as it has been notable in its initial ascent some ten years ago. The singer's fame is in fact now such that its study invokes a sense of banality.

Uncontroversially, I conceive of fame as the quality of being well known, whereas celebrity refers to being known or celebrated for being well known. Despite the possible confusion in terminology, a person who is famous is called a celebrity. Like music, fame is a social relationship with a particular cultural meaning. Music is sociologically understood as the social organization and cultural meaning of the communication of organized sound by a musician towards an audience (Martin 1996). Fame is established relationally between a celebrity and their audience in connection with some achievement, which today most strikingly can indeed be fame itself. The constituent elements of fame and music, as of all things social (Berger and Luckmann 1967), are thus objective, subjective, and inter-subjective.

On the basis of a constructionist perspective of culture, I have elsewhere analysed the sociologically relevant conditions of Lady Gaga's fame as entailing a variety of artistic expressions that are mediated by means of marketing strategies and their legal aspects, activism and feminism, and, as the primary constituents of fame itself, the media and audiences of the singer's fame (Deflem 2017). To be sure, there are other factors as well, but they will be interwoven with those just mentioned. One such case is the naming of the singer as Lady Gaga, such as it has (objectively) taken place as well as the (subjective) presentation and identity of being Lady Gaga and its (inter-subjective) reception and understanding by the audiences of her music and fame. A small tradition of the sociology of naming exists (Finch 2008; Pilcher 2015), but it has not been explored much in connection with fame and celebrity. In what follows, I will show how the naming of Lady Gaga can be examined sociologically in terms of its role as impression management with respect to the various dimensions of fame.

\section{NAMING AS IMPRESSION MANAGEMENT}

My analysis on the naming of Lady Gaga is theoretically framed in the sociology of Erving Goffman. Goffman's 1963 book Stigma is most centrally concerned with discredited identity, but he also discusses the relevance of naming and renaming in establishing personal identity. Goffman (1963, pp. 57-58) specifically argues that a name primarily functions as an identity peg that reveals a person's sex and family lineage. While Goffman briefly mentions that it is 
customary in the world of entertainment for performers to change names, he goes on to argue that the legal name always remains traceable.

Although Goffman is, in line with his focus on stigma, mostly interested in infamy or illfame and its functions of social control, it is noteworthy for the present analysis that he briefly addresses the relevance of fame. Specifically, Goffman (1963, pp. 87-89) describes fame in relation to a group of people who know a person without knowing them personally, that is without relating to them in the face-to-face interaction order, and which can therefore be much wider in composition. The more famous the person, the wider the group of people who know them without knowing them personally.

Goffman's (1956) dramaturgical model in The Presentation of Self in Everyday Life is readily applicable to the world of fame and pop culture as the theory is derived from that very context by suggesting that the theatrical performance can serve as a basis to study how the self is presented to others. Goffman (1956, pp. 10-46) thereby unravels the techniques of the presentation of self as an impression management to impart on others a belief in the role one plays. Dramatization of the self in interaction occurs by highlighting certain notable aspects of one's self, while idealization thereof can be employed to accomplish upward mobility. Any mistakes and difficulties are covered up or concealed. Lastly, Goffman suggests the role of mystification of the dirty work that is involved in playing a role so that the audience will not question the performer.

While Goffman's work is lacking in terms of its systematic theory-building capacity, it can be usefully employed in connection with a constructionist approach to fame. Apart from expressing fame sociologically in a language of relationships, not attributes, the perspective I apply in this paper treats fame as a distinctly cultural phenomenon. In opposition to the reductionists who, following C. Wright Mills (1956) and the culture industry scholars (Horkheimer and Adorno 1944), conceive of fame in terms of its purported function of pacification as a political economy of profit and power, I rely on a neo-Weberian model of fame as a cultural status (Deflem 2017, pp. 20-23; Kurzman et al. 2007). Thus, relevant aspects of naming in terms of Lady Gaga's fame can be related to the interpersonal privileges that are established in mediation with an audience, the economic privilege that comes with a name as a brand, and the legal privileges associated therewith. Within these dimensions of fame, I will analyse the naming of Lady Gaga as a mechanism of impression management in connection with, first, the objective aspects of the history of Lady Gaga's naming and, second, its subjective presentation and intended meaning on the singer's part and the intersubjective reception by her audiences.

\section{THE NAME LADY GAGA}

The history of the naming of Lady Gaga is, even in terms of its objective aspects, not entirely without confusion, something that has functioned to build the mythology around the performer and contributed to her fame (Deflem 2017, pp. 30-37). The singer born on March 28, 1986 in New York City, was named Stefani Joanne Angelina Germanotta by her parents, both of Italian descent. The family (Stefani and her six-year-younger sister Natali) were raised in the Catholic faith, in which the use of multiple first names (rather than the more usual use of a first and a middle name in the USA) is not uncommon. The first name, Stefani, appears to have no family ancestry and may have been chosen precisely because of its singularity. The spelling is not Italian. The singer's second and third first names refer to family members. Joanne was the sister of her father Joe Germanotta, while Angelina refers to her paternal grandmother Angeline. To this day, the singer's parents, sister, and other close relatives refer to her as Stefani or Stef, as 
she was also known among her friends during her teenage years. Father Joe's nickname for her is Loopy. According to her yearbook in high school, a nickname in her teenage years was 'The Germ' (Grigoriadis 2010).

The second name in Lady Gaga's birth name is not insignificant to the singer's career, as she has often used it in her career. The singer's aunt Joanne passed away when she was only 19 years old, on 18 December 1974, a date that Lady Gaga herself cited during the concerts on her Monster Ball concert tour in 2010-2011 upon reciting a short, so-called Manifesto of Little Monster, concerning her relationship with her fans. She also has the date tattooed on her arm in between a quote from one of Rainer Maria Rilke's letters about the passion of writing. On her first album, The Fame, appears "A Poem for Joanne" in the album liner notes, and in 2016, the singer released an album named Joanne, which contains a song of the same name about her aunt's passing. At the time the album was released, the singer referred to herself at live concerts as Joanne and also use that name for fan autographs. Before and since the album, Lady Gaga has, in interviews, often referred to herself as a continuation of the spirit of her aunt, who was said to be artistically gifted and whose memory has been nurtured by her family through various remembrances. Father Joe, since 2012, has operated a restaurant in New York's Upper West Side, just two blocks from where the family has been residing since the early 1990s, called Joanne Trattoria.

The singer known today as Lady Gaga only sporadically performed publicly as a teenager. She began to take her professional music career more seriously, first as a student in musical theatre at New York University, beginning in 2004, and more resolutely after dropping out in March 2005 to seek an independent career in music. She was briefly a band member of a cover group called Mackin Pulsifer but otherwise performed under her birth name, either with or without the last name included, and occasionally with a group, the Stefani Germanotta Band. Most typically she would perform in clubs in New York as Stefani or under the heading "Stefani Live."

No official recordings were released by Stefani, but two self-released demos were sold by the singer at select club performances, and various live performances from 2005 and 2006 are now readily available on YouTube. Among them is a video of a showcase performance at The Cutting Room in New York City on 23 March 2006, nearly one year since she left college, the time her father had given her to make it on her own (Deflem 2017, p. 34). That performance would go on to be a crucial turning point in the transition from Stefani to Gaga as the singer was there seen by fellow singer Wendy Starland, who had been asked by her manager and producer Rob Fusari to be on the look-out for a singer who could function as a performer in the style of the alternative rock band The Strokes. In those days, Stefani's musical style was primarily moulded in a grungy indie-rock style. Starland called Fusari, who had by then acquired a name in the recording industry as producer of such songs as Bootylicious by Destiny's Child, and a week later Stefani met him in his studio in New Jersey. The two would go on to collaborate fruitfully on dozens of songs over the coming months on the basis of a production and artist development contract between the producer and a company representing the singer, Mermaid Music, which was set up by her and her father. Importantly, it was Fusari who first referred to the singer as 'gaga', in reference to her flamboyant style, which the producer thought to be reminiscent of Freddie Mercury of Queen, who had a hit with the song Radio Ga Ga in 1984.

It is perhaps fitting for a singer whose initial rise to fame was in some part related to the assumed or real mythology that existed around various aspects of her persona (Who is she? What is she doing and why?) that even the objective aspects of the choosing of her moniker are somewhat shrouded in mystery. Most often Lady Gaga herself will say that the Gaga nickname 
was adopted by her from Fusari and thereafter used by her friends as well. She has said she later added the suffix 'Lady' to give herself a more rounded, noticeably feminine, and somewhat pretentious artist name. Fusari, however, claims that the expression Lady Gaga was initiated by an accidental autocorrect when he was trying to type out "Radio Gaga" on his phone (Dambrosio 2019). Whatever the case may be, it is certain that the name change to Lady Gaga was formally accomplished by September 2006, when the singer was signed to a recording contract with Island Def Jam. Still appearing in her naturally dark hair, the singer's first known performance as Lady Gaga took place at The Cutting Room on 6 October 2006. What is also certain is that the change from Stefani to Lady Gaga was accompanied by a deliberate transition in her sound and style from indie-rock to electronic dance, a move that at least in part was made in collaboration with Fusari, in view of its anticipated chances of success for a female performer in the pop world.

After having been suddenly dropped by Def Jam a few months after her signing, Lady Gaga began to immerse herself in the underground culture of New York's Lower East Side. There she met another self-named Lady, performance artist and heavy metal DJ Lady Starlight, with whom she would perform glam-oriented pop and rock shows under the heading "Lady Gaga and the Starlight Revue" (Deflem 2017, p. 36). The two also performed together, billed only as Lady Gaga, on a small stage of the Lollapalooza festival in Chicago in August 2007. Although that show failed to garner much attention, Lady Gaga's music was gradually finding its way to the higher executives at Interscope and its parent company Universal, for which Lady Gaga was first hired as a songwriter before she was given a break to establish herself as a performing and recording artist. On 1 January 2008, a now blonde-haired Lady Gaga flew to Los Angeles and began recording music for her first album, The Fame. The debut single Just Dance was released on 8 April 2008. Initially deemed a failure, the song gradually performed well in some countries and radio markets and ultimately went to number one on the Billboard Charts in January 2009, some nine months after its release. From then on, Lady Gaga steadily established herself as a global pop sensation.

\section{BEING (LADY) GAGA: BETWEEN SELF AND OTHERS}

Turning to the subjective meanings that Lady Gaga herself attributes to her name and its intersubjective impact on the audiences of her music and her fame, it is not incidental that the name Lady Gaga itself invokes a notion of mystery and bewilderment, and initially even some ridicule. Unlike other artist names that are not readily recognized as artificial (Bob Dylan, Donna Summer, Freddie Mercury), but also unlike those artist names that are not always understood to be a performer's legal name, whether from birth (Prince) or upon a formal name change (Alice Cooper), the immediate weirdness of the Lady Gaga name relates well to her music and aesthetic persona. Somebody who names herself Lady Gaga is probably more likely to envision a career in the pop world rather than in the serious art world. Explicitly invoking notions of craziness (being gaga), especially in association with an ostensibly formal term (lady), the name fits perfectly with the music and style of her artistry. Lady Gaga herself acknowledged as much when she said the name is fitting because "Gaga is sort of crazy and Lady has such connotations" (quoted in Keegan 2019).

The deliberately, somewhat unsettling nature of the name Lady Gaga ties in with the manner in which the performer sought the limelight of fame, as the name is meant to be confusing precisely to have people wonder who she is. Explicitly framed in the burgeoning celebrity culture days of 2006-2007, with its new class of young (female) celebrities who were famous for being famous, Lady Gaga developed her artistic persona expressly to be noticeable and to feel famous, even when she was not. The fame to which she aspires, she has said, is an 
inner sense of accomplishment based on being aware that "no one knows who you are but everybody wants to know who you are" (quoted in Barton 2009). The name Lady Gaga served to contribute to make this dream come true as the expression readily invokes a question, "who is she?" or, even better yet, "what is she?" When she first appeared on the club scene, the name was received to be so unusual that pop singer Christina Aguilera, who was asked what she thought about the up-and-coming singer, claimed not to know who she was or even to know "if it is a man or a woman" (quoted in Vena 2010). The comment would later sustain the rumour that Lady Gaga might have a penis, despite the inclusion of the gendered suffix Lady in her name (Deflem 2017, pp. 175-176).

The relevance of Lady Gaga's name to the dimensions of the conditions of her fame is most sharply revealed in its use in various media, both those that relate to her artistry and those that make her fame. It is evidently impossible to speak of Lady Gaga without invoking her name, but also, particularly during the formative years of her career, to discuss that name in and of itself, a quality that is lacking with artists who go by their birth name or are unrecognized to have an artist name. As such, the very fact that the name Lady Gaga appears on her albums in all their many forms, ranging from $\mathrm{CD}$ and vinyl to downloads and streaming services, shows the relevance of naming, however tangential it may be to the experience of the content of the music. In this connection, it should be noted that the spelling of the name in print is somewhat controversial. On her recorded music, the singer's name appears in all caps (LADY GAGA), while in liner notes and credits it appears as Lady Gaga, but fans, and indeed the lady herself in her autograph, have at times also written it Lady GaGa.

To know a person is also to know their name. Seeking become known, at the beginning of her career, Lady Gaga would often yell out her name from the stage so that the audience would know who she was. Several of her songs also contain her name in the lyrics, typically at the beginning of the song. Her first hit Just Dance begins with the singer chanting her own name along with those of her producers ("RedOne, Konvict, Gaga"). Other songs feature a similar audio cameo appearance of the Gaga name, such as on Eh, Eh and I Like It Rough, from her debut album, where she chants "Gaga" along with the nickname of the songs' producer ("Cherry Cherry Boom Boom") as well as at the beginning of smash hit Bad Romance ("Gaga-ooh-la-la!"). In Bloody Mary, from the 2011 album Born This Way, the name Gaga is sung in the style of Gregorian chant. Whichever other artistic purpose it might fulfil, the explicit reference to her name in a song will also place it audibly into the mind of the listener.

At live concerts, likewise, the singer often explicitly refers to herself as Lady Gaga - at the beginning of her career to make sure the audience knew who the performer on stage was and later to clearly define herself as the person who not only carries the name but who truly is Lady Gaga. During her highly successful 2010-2011 Monster Ball tour, the singer introduced a short spoken-word narrative about self-worth by screaming loudly and proudly, "My name is LADY GAGA!" During a short run of live performances at New York's Roseland Ballroom in 2014, merchandise was sold that contained the even stronger expression "Lady Fucking Gaga," the message being she is not only Lady Gaga but is also here to stay, like it or not.

The naming of Lady Gaga has arguably shown its most explicit impact with respect to the media of her fame, inasmuch as her name has been explicitly discussed, even recently, some ten years into her successful and firmly established career, in various news media on TV, radio, in print, and on the internet. Reviewing some of the earliest cover stories about the singer in influential news outlets such as Rolling Stone, Vanity Fair, and Vogue, all of these early reports comment on the singer's biography, including stories on her childhood and the years before her rise to fame, additionally being careful to mention her birth name and an explanation of the 
origins of her artist name (Hiatt 2009; Robinson 2010; Van Meter 2011). News items telling the story of Lady Gaga's name appear until this day, typically in online articles with such banal titles as "How Lady Gaga got her name" or "What is Lady Gaga's real name?" (Dambrosio 2019; Keegan 2019). The ever-popular type of kitsch articles that involve some kind of faked "Did you know...?" or "X-number of things you did not know about..." deal with the singer's birth name and the origins of her stage name, even in recent years (Joyce 2018; Vogue 2019). No doubt a function of the ease with which all kinds of nonsense flourishes on the internet, it nonetheless also shows a continued obsession with the singer and anything related to her, including her name.

Lady Gaga is arguably among the best examples in the digital era to have connected so well with her many and large audiences, an issue that has received all due academic attention as well (Bennett 2014; Click, Lee and Holladay 2017). In this mediation of the singer's music and fame, her name has revealed several practical advantages. The global reception of the name benefits from it being made up of relatively common terms, as the words "lady" and, even more so, "gaga" are relatively universal. Importantly, the connections Lady Gaga has thereby successfully established relate not only to her fans, but to a much broader audience of fans, nonfans, and anti-fans, all of whom are watching her (Deflem 2017, pp. 125-127). In terms of the various and widely appealing styles of her music and artistry, also, the singer benefits from the emphasis in her name shifting from the first term to the second or, vice versa, from the second to the first as she moves in and out of contemporary pop as well as jazz, acting, and celebrity advocacy (Deflem 2019).

Corresponding to Lady Gaga's successful use of various media, the devotion of her most dedicated fans is likewise a notable feat that has received much scholarly attention (Click, Lee, and Holladay 2013; Dilling-Hansen 2015a, 2015b; Huba 2013). From the viewpoint of this paper, an important aspect of naming is that Lady Gaga also gave a unique name to her hardcore fans (Deflem 2017, pp. 127131). While preparing the release of her album The Fame Monster in the summer of 2009, she began to refer to her fans during live shows as Little Monsters, a term that she from then on developed more explicitly by communicating it to her fans and, effectively, having them adopt it as theirs. Correspondingly, the singer at times refers to herself as Mother Monster.

Lady Gaga's naming of her fans is reminiscent of other music fan bases with their own unique names. Yet, the Little Monsters carry a name (and use the symbol of the so-called "monster claw" that was likewise suggested by the singer herself) that was deliberately invented and subsequently widely, if not universally, adopted by her most loyal fans. The general audience likewise use the term when referring to the singer's most devoted followers as a component of her performance. Like the name Lady Gaga, the term Little Monsters creates attention and thus functions as a source of fame, a phenomenon that in the world of pop music has been accelerated since Lady Gaga, with varying levels of success (e.g., Beliebers, Swifties, Lovatics, Arianators, Fighters, and all too many others).

While it is not useful to conceive of celebrity as an exclusive function of media industry forces (Couldry 2016), it is also true that a successful career cannot be maintained without an appropriate infrastructure. As such, Lady Gaga also needs to be marketed so that her products can be sold and bought. Besides various sponsorships and company tie-ins, Lady Gaga derives her wealth from recording and performing as Lady Gaga and from selling related merchandise (Deflem 2017, pp. 62-64). In part as a result of the fact that contemporary pop stars cannot survive from selling recorded music alone, and in view of her many talents, Lady Gaga has presented herself, and is generally understood, as a multitalented artist, a singer and musician 
of pop, rock, and jazz, an actress, a fashion icon, and an activist, among other roles she successfully performs.

Hand in hand with the marketing of Lady Gaga as a product are a series of legalities involved with the business aspects of her career. As a performer who engages in a variety of contractual obligations, Lady Gaga is usually not named as such nor by her birth name, but instead is represented by a legal entity that is a company. For her business ventures, Lady Gaga (and her father) set up the limited liability company Mermaid Music in March 2005, when she first engaged in a contract with producer Fusari (Deflem 2017, p. 76). Other, related companies that have since been set up include the functionally specialized Mermaid Touring and Mermaid Music Management. The singer's publishing interests are overseen by House of Gaga Publishing, while her trademarks are represented by the company Ate My Heart.

Litigation involving Lady Gaga has taken place as a direct function of her success and fame, involving contractual obligations, copyright violations, and trademark infringements (Deflem 2017, p. 76). Contracts are signed with one of Lady Gaga's companies, and any related litigation involves those companies as well as the singer herself, who is then typically mentioned as "Stefani Germanotta aka Lady Gaga." One of the few instances where Lady Gaga uses her birth name, Stefani Germanotta, is in matters involving her songs' copyrights, such as the registration of her songs with the performing rights organization Broadcast Music, Inc. to collect licensing fees and royalties (Deflem 2017, p. 79).

Legal aspects of trademark involve regulations concerning the very name Lady Gaga and the products that are legally secured in association with that name (Deflem 2017, pp. 77-79). Defending the rights to use Lady Gaga's name, the company Ate My Heart has successfully acquired some 50 trademarks, involving the name "Lady Gaga" in association with music recordings as well as a variety of clothing and beauty products. Related names for which Ate My Heart has secured trademark include the names of some of her songs such as Bad Romance and $A R T P O P$, the name of her creative team "Haus of Gaga", and the name she coined for her fans "Little Monsters", among others. Since 2010, at least 35 trademark claims have been pursued by Ate My Heart for all kinds of named goods and services that were argued to involve trademark violations, such as a video song called Lady Goo Goo and the breastmilk-derived ice-cream brand, Baby Gaga. Not all of these litigations have been ruled in Lady Gaga's favour. At times, not even the name Lady Gaga can help.

\section{THE NAME OF FAME}

The name Lady Gaga has functioned as a device that sought and has attained attention. Not only has the name of Lady Gaga in several ways contributed to her fame, that fame is in turn also expressed through the singer's name. It could be no different, inasmuch as a necessary condition of fame is having a name and having it be known. Thus, Goffman's (1963) notion of the identity peg in the case of a celebrity's name becomes a necessary, if insufficient, condition of fame. Applied to the case at hand, it would be too obvious to question the fact that Lady Gaga has been able to establish her career primarily as the result of her talents in music and, from there, her accomplishments in other ventures such as fashion and acting. People enjoy Lady Gaga primarily because and inasmuch as they like the many tangible expressions of her aesthetic persona. But there is also no doubt that, in Lady Gaga's case, there is much in a name.

Subjectively, Lady Gaga presents herself consistently as Lady Gaga. As an indication of her own understanding of self, the singer would, at the concerts of her first head-lining tour The Fame Ball in 2009, admit that Lady Gaga is a lie, but also go on to say that she would kill to make it true (Caramanica 2009). This transformation of Lady Gaga from an ideal to an achievement 
corresponds to the singer's notion of the fame that grows out of an initial delusion, to become famous by feeling and acting famous before one is famous. Once established, Lady Gaga never wants to not be Lady Gaga, with the possible exception of her very smallest circles of family and intimate friends and boyfriends, who, by definition, we can never fully know. In 2010, she still used her birth name to position herself as involved as a citizen in political activism, such as when she spoke out against the "Don't Ask Don't Tell” policy against gay people in the US military (Deflem 2017, pp. 149-150). But since those days, Lady Gaga has become the only name of her persona, although she has not gone so far as to legally change her name and is unlikely to ever do so. Even Lady Gaga is not that gaga. The singer did recently, however, have her name tattooed on her arm in its corresponding musical notes (G-A-G-A) and uses a design with the letters on her current twitter feed, possibly in anticipation of her new album.

Inter-subjectively, likewise, the audiences of Lady Gaga's fame refer to the singer by her name. Journalists in the mass media sometimes include a reference to her birth name, as if this constitutes some type of special revelation or indication of her lack of authenticity in favour of the legally endowed objectivity of her birth name, which is designated as her "real" name. For all intents and purposes, however, the essence of Lady Gaga today is that she is Lady Gaga, even though she briefly called herself Joanne during the Joanne World Tour and once "Enigma" in preparation of her Las Vegas residency (Dambrosio 2019). Her birth name, in any case, is as irrelevant to pop culture as are those of Vincent Furnier, Stevland Hardaway Morris, and Paul Hewson. During the promotion of the movie A Star Is Born, the singer reaffirmed herself explicitly as Lady Gaga after rumours had circulated that she would be billed as Stefani Germanotta, probably as a result of co-star Bradley Cooper referring to her by her first name in the media (Muller 2017). In the movie, Lady Gaga plays a singer called Ally, a role perhaps not too far from, but nonetheless different from herself, as Ally is reluctant to pursue the fame ultimately bestowed on her.

From a constructionist perspective of fame as a cultural phenomenon, I reveal the name Lady Gaga to be influential at several levels, even including the mysteries surrounding its objective history, but especially revealing itself relationally in terms of the singer's presentation of self to others, including the fans of her music and the audience of her fame, the media she uses, and her marketing and its legalities. This perspective runs counter to the scholarship of fame and celebrity that rests on a political economy of fame and accordingly reduces the naming functions in fame as branding, especially when it pertains to pop culture. In his analysis of the rise to fame of pop group New Kids on the Block, for example, David Marshall (1997) highlights, among other matters, aspects of the name of the band as the name of a brand. The naming aspects of pop thus appear as an economic marketing issue, with the name of the pop icon representing a commodity that attracts an audience of buyers. "Maintaining consistency around the name," Marshall (1997, p. 181) writes, "ensured a degree of brand loyalty among music consumers."

As my analysis has shown, it is not useful to reduce culture to economy, not even in pop, as the naming of Lady Gaga exerted itself in various ways, some of which, to be sure, also reveal the lady as a brand. But there is more. In many ways, Lady Gaga is the exact opposite of a brand because the singer herself was largely in charge of the construction of her own identity and its naming. The relationship her fans, the Little Monsters, establish with Lady Gaga is deeply emotional and cannot be bought, nor can they simply be thought of as having been fooled by a lie. To her fans, Lady Gaga is simply Gaga, and she need not be called Lady, suggesting an intimacy that is established by referring to the singer on the basis of her adopted first name rather than the formality that is suggested by any last name (Marshall 1997, p. 144). Calling her Gaga establishes a closeness that is akin to that of a friend and probably more authentic than 
many of those who think they can refer to her as Stef. For her personal friends who now call her Gaga (as many of them now do), the situation is reversed, although the distance that is ironically created by those who used to know her as Stef is offset by the fact that they can count one of the world's most famous celebrities among their friends.

In Goffman's terms of impression management, the naming of Lady Gaga has aided in establishing her as an artist, especially inasmuch as her name functioned as a combination of dramatization, idealization, and mystification. As a result, Lady Gaga has been successful, as a celebrity among celebrities, in manipulating the structural conditions of her presentation of self to further her popularity and its associated interpersonal, economic, and legal privileges.

Although Lady Gaga engaged in her own naming process early on in her career, to insert herself into the world of pop, she has since continued to affirm and re-affirm herself as Lady Gaga. This reiterative process of claiming to be, and thus publicly becoming, Lady Gaga has not only normalized her name, but also allowed her to fill in more liberally the meaning(s) associated with that name. Indeed, what Lady Gaga stands for in this ongoing process of nameaffirmation is now much more than just a singer of catchy electro-pop songs, but instead has become a versatile artist who can just as easily sing pop as jazz, play classical piano, act in movies, and engage in political and activist causes. A key element that has enabled the formation of this multi-dimensional persona is Lady Gaga's identity as a performance artist, which not only accepts but "embraces the possibility of transformation" (Auslander 2016, p. 186). As this process of creating a multitalented Lady Gaga continues, she has begun to be perceived, not as just a pop star, but as an accomplished and respectable artist.

In the Goffmanian sociology of the self, the question emerges how the multiplicity of selves and their various roles are balanced and negotiated. Lady Gaga herself is firm on this matter, at least by stated intent, as she conceives of herself as full-time Lady Gaga (Deflem 2017, p. 63). In interviews early in her career, for instance, she would often have to explain where the name Lady Gaga came from and if her friends and relatives call her Gaga. Rarely would she admit that her family and close friends held on to Stef or Stefani, instead emphasizing that everybody calls her Gaga and even suggesting, no doubt falsely, that the name was already used by her friends before she formally adopted it (Dambrosio 2019). The only known exceptions to which the singer has admitted are her parents, especially her father, and her boyfriends. On her album The Fame Monster, the song Alejandro contains the oft-repeated line "don't call my name", to denote the anonymity the singer prefers to enjoy when having casual sex with unknown men who she in turn generically labels as just one of many Alejandros, Fernandos, and Robertos. The song Monster, about a sexual exploit, begins with the singer softly singing "Don't call me Gaga," as if she realizes the ridiculousness of still maintaining to be Lady Gaga when she is having sex with a man.

Inasmuch as Lady Gaga is now always Lady Gaga, there is no more private self that is not Gaga. Besides, although she rose to the top of the pop world because of her electro-pop dance songs, the performer has since proven her worth as a multi-dimensional artist. The moniker Lady Gaga has thereby allowed the performer to play different versions of herself or different selves. Theoretically, an interesting problem presents itself: how can this multiplicity be captured in terms of the concept of persona? Whereas Philip Auslander (2014, p. 188) suggests, explicitly in connection with Lady Gaga, the possibility of performance artists generating "multiple personae", I argue it is conceptually sounder to adopt the notion of a persona (in the singular) that is multi-dimensional and versatile. After all, the various manifestations of Lady Gaga's artistry and identity co-exist in the same person and do not appear as discrete entities. As such, Lady Gaga exists and performs, in Kate Warren's (2016) words, as a "parafictional 
persona" who can drift in and out of a variety of public roles, while always being true to her own self. As such, the performer can be said to exist, in the words of Lady Gaga herself, "halfway between reality and fantasy" (quoted in Kelly 2011).

\section{CONCLUSION}

Naming has played a distinct role in the career of Lady Gaga. Discussions about and with Lady Gaga during the beginning of her career and fame, not least of all dealing with her career and fame, did much to increase her visibility. Likewise, talk about her name did much to promote her fame. Even her fans and her audience are not immune to this process as they, naturally, become referred to, by name, as Lady Gaga fans and members of the Lady Gaga audience. Only jazz singer and sometime Lady Gaga collaborator Tony Bennett calls her Lady, as if it is her first name. The only other time that occurred, with all due comedic effects, was at a press conference for the movie A Star Is Born at the Venice Film Festival, where Lady Gaga's name on a nameplate was abbreviated, similar to Bradley Cooper's “B. Cooper”, to “L. Gaga” (Rosenberg 2018). Namerelated humour was deliberately pursued when Lady Gaga appeared in a mock TV quiz show sketch called "What's That Name?" on the popular comedy show Saturday Night Live in May 2011. In the sketch, Lady Gaga knows everybody she has ever met by name, even a fan called Alphonse she's supposedly seen only once before (Deflem 2017, p. 227).

There is no denying that since, and at least partly because of, Lady Gaga, dozens of other performers in popular music have recently sprung up with rather unusual names. Although they may not have been singularly influenced by Lady Gaga, there is no doubt that her success and fame did contribute to a normalization of the reception of such contemporary performers as FKA Twigs, SZA, St. Vincent, Grimes, and M.I.A. What is also striking is that the naming of these artists remains a source of debate and curiosity in the media, even though the use of pseudonyms in popular music can rely on a long tradition. It is worthy of further research to examine if and why such discussions are gendered, as especially women performers are the object of such popular contemplations. In pop culture, it appears that the question 'who's that girl?' is asked much more than its male equivalent. More broadly, more systematic research is needed to estimate whether the case of Lady Gaga is relatively unique or can be generalized to a broader universe.

It is not only in line with a focus on the conditions of Lady Gaga's fame, but also particularly because Lady Gaga has now become a household name, that the emphasis in this paper has been particularly concerned with the role of naming in the performer's initial rise to fame, rather than its further development when attention on her name decreased, even though it did not become any less relevant. That very fact shows the success of Lady Gaga's naming as a technique of impression management. Yet, there has most recently been some change in how Lady Gaga relates to her name and its relation to her birth name, especially since she has begun to venture more seriously into acting. Speaking of her role in A Star Is Born and director Bradley Cooper, she has said, "I ran from Stefani for a long time and I put on a superhero cape and called myself Lady Gaga. He challenged me to deep dive into a place where I had to see her again" (quoted in Botticello 2018). But despite this one-time proclamation that there still would be a Stefani Germanotta, she was adamant to confirm her billing in the movie by tweeting "It's Lady Gaga, baby!" (quoted in Muller 2017). If it is true, as Goffman suggested, that the celebrity is a non-celebrity only where they are not known and where the personal nature of relationships overrides the celebrity's fame, Lady Gaga today is virtually everywhere and always Lady Gaga. 


\section{WORKS CITED}

Auslander, P 2014, 'Barbie in a meat dress: Performance and mediatization in the $21^{\text {st }}$ century', in K Lundby (ed.), Mediatization of Communication, de Gruyter, Berlin, pp. 505-524.

Auslander, P 2016, 'Twenty-first century girl: Lady Gaga, performance art, and glam', in I Chapman \& H Johnson (eds), Global Glam and Popular Music, Routledge, New York, pp. 182-198.

Barton, L 2009, '"I've felt famous my whole life"', The Guardian, January 20, retrieved 14 March 2019, http://www.theguardian.com/music/2009/jan/21/lady-gaga-inter-view-fame

Bennett, L 2014, 'Fan/celebrity interactions and social media: Connectivity and engagement in Lady Gaga fandom', in L Duits, K Zwaan, \& S Reijnders (eds), The Ashgate Research Companion to Fan Cultures, Ashgate, Surrey, pp. 109-120.

Berger, PL \& Luckmann, T 1967, The Social Construction of Reality, Anchor, New York.

Botticello, M 2018, 'Lady Gaga fights back tears while honoring Bradley Cooper at American Cinematheque Gala', Variety, November 30, 2018, retrieved 14 March 2019, https://variety.com/2018/scene/news/bradley-cooper-american-cinematheque-ladygaga-1203065837/

Caramanica, J 2009, 'An artist whose chief work is herself', The New York Times, May 3, 2009, http://www.nytimes.com/2009/05/04/arts/music/04gaga.html.

Click, MA, Lee, H \& Holladay, HW 2013, 'Making monsters: Lady Gaga, fan identification, and social media', Popular Music and Society, vol 36, no. 3, pp. 360-379.

Click, MA, Lee, H \& Holladay, HW 2017, “'You're born to be brave”: Lady Gaga's use of social media to inspire fans' political awareness', International Journal of Cultural Studies, vol. 20, no. 6, pp. 603-619.

Couldry, N 2016, 'Celebrity, convergence, and the fate of media institutions', in DP Marshall \& $\mathrm{S}$ Redmond (eds), A Companion to Celebrity, Wiley Blackwell, Chichester, UK, pp. 98- 113.

Dambrosio, C 2019, 'How Lady Gaga came up with her famous name', Insider, January 11, 2019, retrieved 14 March 2019, https://www.thisisinsider.com/how-lady-gaga-got-her-name2019-1

Deflem, M 2017, Lady Gaga and the Sociology of Fame: The Rise of a Pop Star in an Age of Celebrity, Palgrave Macmillan, New York.

Deflem, M 2019, 'The new ethics of pop: Celebrity activism since Lady Gaga', in M Stramaglia (ed.), Pop Cultures: Sconfinamenti Alterdisciplinari, Pensa Multimedia, Lecce-Rovato, Italy, pp. 113-129.

Dilling-Hansen, L 2015a, 'Affective fan experiences of Lady Gaga', Transformative Works and Cultures, vol. 20, online, https://doi.org/10.3983/twc.2015.0662.

Dilling-Hansen, L 2015b, 'A strategic romance? On the affective relation between Lady Gaga and her Little Monsters in online communication', in ID Sharma \& F Tygstrup (eds),

Structures of Feeling: Affectivity and the Study of Culture, de Gruyter, Berlin, pp. 216-225.

Finch, J 2008, 'Naming names: Kinship, individuality and personal names', Sociology, vol. 42, no. 4, pp. 709-725.

Goffman, E 1956, The Presentation of Self in Everyday Life, University of Edinburgh Social Sciences Research Centre, Edinburgh.

Goffman, E 1963, Stigma: Notes on the Management of Spoiled Identity, Prentice-Hall, Englewood Cliffs, NJ.

Gray, RJ (ed.) 2012, The Performance Identities of Lady Gaga: Critical Essays, McFarland, Jefferson, NC.

Grigoriadis, V 2010, 'Growing up Gaga', New York Magazine, March 28, 2010, retrieved 14 March 2019, http://nymag.com/arts/popmusic/features/65127/

Hiatt, B 2009, 'Lady Gaga: New York doll', Rolling Stone, June 11, 2009, retrieved 14 March 2019, http://www.rollingstone.com/music/news/lady-gaga-new-york-doll-rolling- stones2009-cover-story-20090611 
Horkheimer, M \& Adorno, TW (1944) 1972, Dialectic of Enlightenment, Herder and Herder, New York.

Huba, J 2013, Monster Loyalty: How Lady Gaga Turns Followers into Fanatics, Portfolio/Penguin, New York.

Iddon, M \& Marshall, ML (eds) 2014, Lady Gaga and Popular Music: Performing Gender, Fashion, and Culture, Routledge, London.

Joyce, M 2018, '11 fun facts you never knew about Lady Gaga that prove she's on the right track, baby', Odyssey, April 3, 2018, retrieved 14 March 2019, https://www.theodysseyonline.com/lady-gaga-facts

Keegan, K 2019, 'How Lady Gaga got her name and why she doesn't use her real one', Good Housekeeping, January 7, 2019, retrieved 14 March 2019, https://www.goodhousekeeping.com/life/entertainment/a25737162/how-did-ladygaga-get-her-name/

Kelly, K 2011, 'Lady GaGa: “My personas have blurred into one”', Digital Spy, September 7, 2011, retrieved 14 March 2019, https://www.digitalspy.com/showbiz/a329029/lady-gagamy-personas-have-blurred-into-one/

Kurzman, C, Anderson, C, Key, C, Lee, YO, Moloney, M, Silver, A \& Van Ryn, MW 2007, 'Celebrity status', Sociological Theory, vol. 25, no. 4, pp. 347-367.

Marshall, PD 1997, Celebrity and Power: Fame in Contemporary Culture, University of Minnesota Press, Minneapolis, MN.

Marshall, PD, Moore, C. \& Barbour, K 2020, Persona Studies: An Introduction, Wiley Blackwell, Hoboken, NJ.

Marshall, PD \& Redmond, S (eds) 2016, A Companion to Celebrity, Wiley Blackwell, Chichester, UK.

Martin, PJ 1996, Sounds and Society: Themes in the Sociology of Music, Manchester University Press, Manchester, UK.

Mills, CW 1956, The Power Elite, Oxford University Press, New York.

Muller, MG 2017, 'Lady Gaga says she will not be billed as her real name, Stefani Germanotta, for A Star Is Born', W Magazine, December 12, 2017, retrieved 14 March 2019, https://www.wmagazine.com/story/lady-gaga-using-stage-name-for-a-star-is-born

Pilcher, J 2015, Names, bodies and identities, Sociology, vol. 50, no. 4, pp. 764-779.

Robinson, L 2010, 'Lady Gaga's cultural revolution', Vanity Fair, September 2010, pp. 280-286, 329-331.

Rosenberg, L 2018, “These “L. Gaga” memes about Lady Gaga's Venice Film Festival nameplate are too good', Elite Daily, September 1, 2018, retrieved 14 March 2019, https://www.elitedaily.com/p/these-l-gaga-memes-about-lady-gagas-venice-filmfestival-nameplate-are-too-good-11477415

Turner, G 2014, Understanding Celebrity, $2^{\text {nd }}$ edition, Sage, London.

Van Meter, J 2011, 'Lady Gaga: Our lady of pop', Vogue, February 10, retrieved 14 March 2019, http://www.vogue.com/865458/lady-gaga-our-lady-of-pop/

Vena, J 2010, 'Christina Aguilera on Lady Gaga comparisons: "My work speaks for itself"', MTV.com, April 21, 2010, retrieved 14 March 2019, http://www.mtv.com/news/1637525/christina-aguilera-on-lady-gaga-comparisonsmy-work-speaks-for-itself/

Vogue 2019, '5 things you didn't know about Lady Gaga', Vogue, January 6, 2019, retrieved 14 March 2019, https://www.vogue.com/article/lady-gaga-5-things-you-didnt-know

Warren, K 2016, 'Double trouble: Parafictional personas and contemporary art', Persona Studies, 2(1), 55-69. 